\title{
RATE ENHANCEMENT IN CONTROLLED RADICAL POLYMERIZATION OF ACRYLATES USING RECYCLABLE HETEROGENEOUS LEWIS ACID
}

\section{Rong Luo and Ayusman Sen*}

\section{Department of Chemistry,}

The Pennsylvania State University, University Park, PA 16802

\section{*E-mail: $\underline{\text { asen@psu.edu }}$}

\section{Experiment section}

Materials. All chemicals and reagents were obtained from Aldrich unless otherwise stated. Methyl acrylate (MA, 99\%), n-butyl acrylate (BA, 99\%), and 1-hexene were vacuum distilled from $\mathrm{CaH}_{2}$ and stored under $\mathrm{N}_{2}$. 2, 2'-Azobis(isobutyronitrile) (AIBN, 98\%), aluminum oxide (activated, acidic, Brockmann I, standard grade, 150 mesh, $\mathrm{pH}=4.5 \pm 0.5$ in aqueous solution $)$, and scandium triflate $\left(\mathrm{Sc}(\mathrm{OTf})_{3}, 98 \%\right)$ was used as received.

The NMP initiator, 2, 2, 5- trimethyl- 3- (1-phenylethoxy)-4-phenyl-3-azahexane, and the NMP control agent, 2, 2, 5- trimethyl-4-phenyl-3-azahexane-3-nitroxide, were synthesized and purified following literature procedure [Benoit, D.; Chaplinski, V.; Braslau, R.; Hawker, C. J. J. Am. Chem. Soc. 1999, 121, 3904-3920]. The RAFT agent, benzyl 1-pyrrolcarbodithioate was synthesized and purified following literature procedure [Chiefari, J.; Mayadunne, R. T. A.; Moad, C. L.; Moad, G.; Rizzardo, E.; Postma, A.; Skidmore, M. A.; Thang, S. H. Macromolecules 2003, 36, 2273-2283]. 
Instrumentation. ${ }^{1} \mathrm{H}$ - and ${ }^{13} \mathrm{C}-\mathrm{NMR}$ spectra were recorded using a Bruker $300-\mathrm{DPX}$ spectrometer at ambient temperature ( $\left.{ }^{1} \mathrm{H}-\mathrm{NMR}, 300 \mathrm{MHz} ;{ }^{13} \mathrm{C}-\mathrm{NMR}, 75 \mathrm{MHz}\right)$. Chemical shifts are referenced to $\mathrm{CDCl}_{3}$. Molecular weights and polydispersities were determined on a Shimadzu gel permeation chromatography (GPC) chromatograph containing a three-column bed (styragel HR $7.8 \times 300 \mathrm{~mm}$ columns with $5 \mu \mathrm{m}$ beads size; 100-5000, 500-30,000, and 2,000-4 × 10 $0^{6} \mathrm{Da}$ ), a Shimadzu RDI-10A differential refractometer, and a Shimadzu SPD-10A tunable absorbance detector (254 nm). GPC samples were run in tetrahydrofuran at a flow rate of $1 \mathrm{ml} / \mathrm{min}$ at $35^{\circ} \mathrm{C}$ and calibrated against polystyrene standards. Analysis was done using EZSTART 7.2 software.

Kinetic study of nitroxide mediated polymerization of BA in the presence and absence of acidic alumina. In a $\mathrm{N}_{2}$-filled dry box, a round bottom flask equipped with a magnetic stir bar was charged with NMP initiator (195 mg, 1.0 equiv.), NMP control agent (6 mg, 0.05 equiv.), BA (9.6 g, 125 equiv.), internal standard tetrachloroethane (TCE, $0.5 \mathrm{~g}$ ), acidic alumina (0.765 g, 1:10 to monomer) and chlorobenzene $(20 \mathrm{ml})$. The flask was then placed in an oil bath at $125^{\circ} \mathrm{C}$. Samples were taken at specific time intervals using a syringe and analyzed by GC. The conversion of BA was calculated from the integration of BA peak with respect to TCE peak. The molecular weight was measured by GPC. 


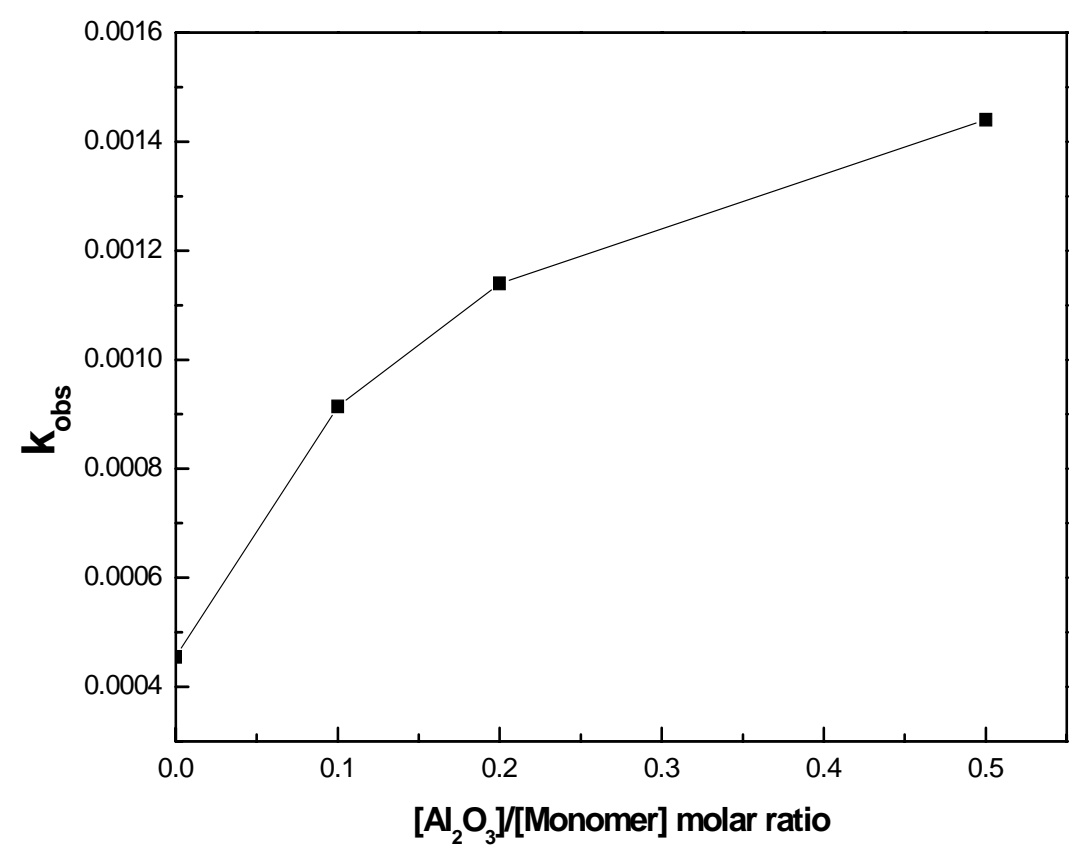

Figure S1. Dependence of observed $n$-butyl acrylate polymerization rate on $\left[\mathrm{Al}_{2} \mathrm{O}_{3}\right] /[$ monomer] molar ratio. Conditions: NMP initiator (2,2,5-trimethyl-3-(1phenylethoxy)-4-phenyl-3-azahexane), $0.6 \mathrm{mmol}$; NMP control agent (2,2,5-trimethyl4-phenyl-3-azahexane-3-nitroxide), $0.03 \mathrm{mmol}$; BA, $75 \mathrm{mmol}$; Tetrachloroethane (TCE), $0.5 \mathrm{~g}$; PhCl, $20 \mathrm{~mL} ; 125^{\circ} \mathrm{C}$.

General procedure for nitroxide mediated polymerization of BA in the presence of acidic alumina. In a $\mathrm{N}_{2}$-filled dry box, a mixture of NMP initiator (33 mg, 1.0 equiv.), NMP control agent (1 mg, 0.05 equiv.), BA (3.2 g, 250 equiv.), acidic alumina (0.255 g, 1:10 to monomer) and chlorobenzene $(5 \mathrm{ml})$ was sealed in $20 \mathrm{ml}$ scintillation vial. The reaction mixture was allowed to stir in a $125^{\circ} \mathrm{C}$ oil bath for $18 \mathrm{~h}$. At the end of this period, the alumina was removed by filtration, and the polymer was precipitated with a large excess of methanol. The polymer was collected by filtration and dried under high vacuum for $24 \mathrm{~h}$. 
Table S1. Nitroxide-mediated polymerisation (NMP) of n-butyl acrylate in the presence of acidic $\mathrm{Al}_{2} \mathrm{O}_{3}{ }^{\mathrm{a}}$.

\begin{tabular}{|c|c|c|c|c|c|c|c|}
\hline Entry & $\begin{array}{l}{[\mathrm{M}]} \\
(\mathrm{g})\end{array}$ & {$[\mathrm{M}] /[\mathrm{I}]$} & $\begin{array}{l}\text { BA } \\
\text { Conv. (\%) }\end{array}$ & $\begin{array}{l}M_{n} \text { expt. } \\
\left(x 10^{-4}\right)^{b}\end{array}$ & $\begin{array}{l}\mathrm{M}_{\mathrm{n}} \text { theo. } \\
\left(\mathrm{x} 10^{-4}\right)\end{array}$ & $\begin{array}{l}\text { PDI } \\
\left(M_{w} / M_{n}\right)^{b}\end{array}$ & $\begin{array}{l}\text { Recycled } \\
\mathrm{Al}_{2} \mathrm{O}_{3}(\%)\end{array}$ \\
\hline 1 & 12.8 & 1500 & 25 & 5.27 & 4.81 & 1.11 & 98 \\
\hline 2 & 9.6 & 1125 & 31 & 4.91 & 4.47 & 1.14 & 99 \\
\hline 3 & 6.4 & 750 & 34 & 3.54 & 3.27 & 1.15 & 99 \\
\hline $4^{c}$ & 6.4 & 250 & 47 & 1.70 & 1.51 & 1.16 & 97 \\
\hline $5^{\mathrm{c}}$ & 3.2 & 125 & 59 & 1.10 & 0.95 & 1.15 & 95 \\
\hline 6 & 1.6 & 188 & 33 & 0.84 & 0.79 & 1.15 & 98 \\
\hline
\end{tabular}

${ }^{\mathrm{a}}$ Conditions: $\mathrm{Al}_{2} \mathrm{O}_{3}, 1: 10$ (mol ratio) to monomer; NMP initiator (2,2,5-trimethyl-3-(1phenylethoxy)-4-phenyl-3-azahexane), 1.0 equiv; NMP control agent (2,2,5trimethyl-4-phenyl-3-azahexane-3-nitroxide), 0.05 equiv; $125^{0} \mathrm{C}$. ${ }^{\mathrm{b}} \mathrm{By}$ GPC (THF) relative to polystyrene standards. ${ }^{\mathrm{c}} \mathrm{Runs}$ that using recycled $\mathrm{Al}_{2} \mathrm{O}_{3}$.

Kinetics study of nitroxide mediated polymerization of styrene in the presence and absence of acidic alumina. In a $\mathrm{N}_{2}$-filled dry box, a round bottom flask equipped with a magnetic stir bar was charged with NMP initiator (98 mg, 1.0 equiv.), NMP control agent (3 mg, 0.05 equiv.), styrene (3.9 g, 125 equiv.), internal standard tetrachloroethane (TCE, $0.5 \mathrm{~g})$, acidic alumina $(0.382 \mathrm{~g}, 1: 10$ to monomer) and chlorobenzene $(10 \mathrm{ml})$. The flask was then placed in an oil bath at $125^{\circ} \mathrm{C}$. Samples were taken at specific time intervals using a syringe and analyzed by GC. The conversion of styrene was calculated from the integration of styrene peak with respect to TCE peak. The molecular weight was measured by GPC. 


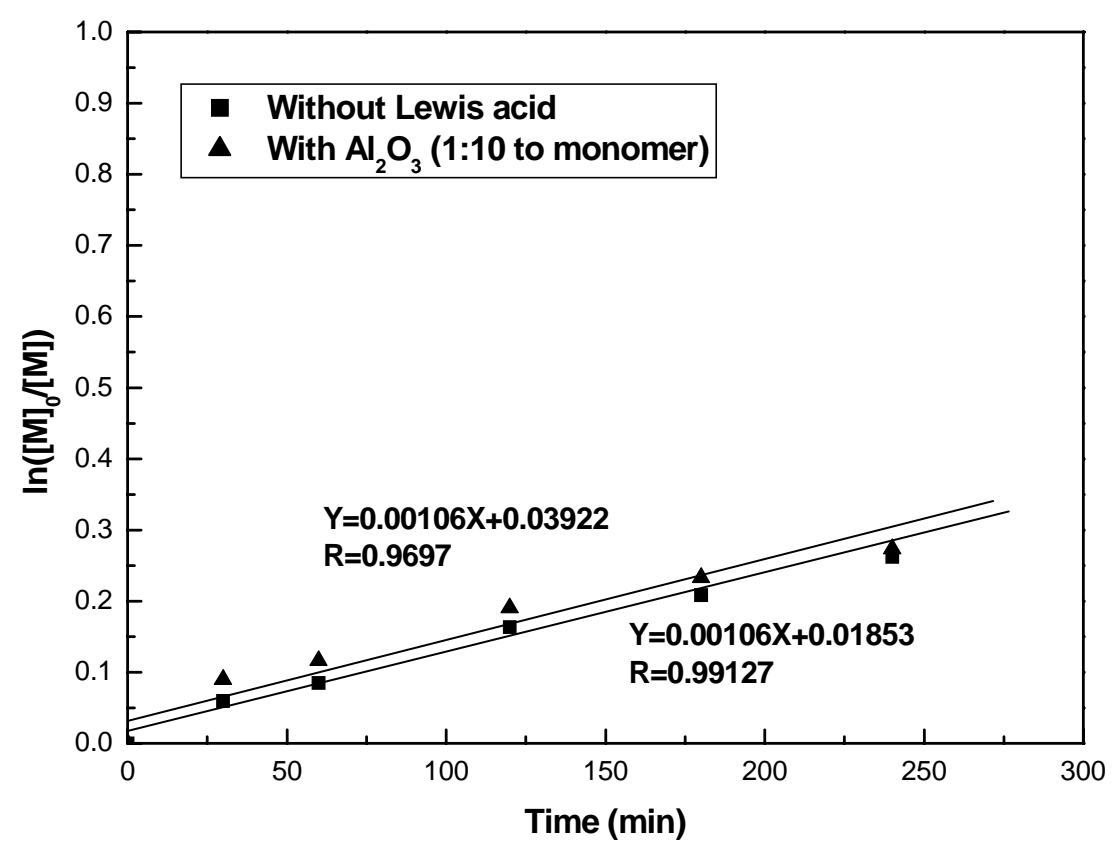

Figure S2. Kinetics study of nitroxide mediated homopolymerization of styrene in the presence and absence of Lewis acid. Conditions: NMP initiator (2,2,5-trimethyl-3-(1phenylethoxy)-4-phenyl-3-azahexane), $0.3 \mathrm{mmol}$; NMP control agent (2,2,5-trimethyl4-phenyl-3-azahexane-3-nitroxide), $0.015 \mathrm{mmol}$; Styrene, $38 \mathrm{mmol}$; Tetrachloroethane (TCE), $0.5 \mathrm{~g} ; \mathrm{PhCl}, 10 \mathrm{~mL} ; 125^{\circ} \mathrm{C}$.

\section{General procedure for block copolymer formation: preparation of poly(n-butyl} acrylate)-b-polystyrene. In a $\mathrm{N}_{2}$-filled dry box, a mixture of NMP initiator (33 mg, 1.0 equiv.), NMP control agent ( $1 \mathrm{mg}, 0.05$ equiv.), BA (3.2 g, 250 equiv.), acidic alumina (0.255 g, 1:10 to monomer) and chlorobenzene $(5 \mathrm{ml})$ was sealed in $20 \mathrm{ml}$ scintillation vial. The reaction mixture was allowed to stir in a $125^{\circ} \mathrm{C}$ oil bath for $18 \mathrm{~h}$. At the end of this period, the polymer was precipitated with a large excess of methanol. The colorless polymer was collected by filtration and dried under high vacuum for $24 \mathrm{~h}$. The poly(n-butyl acrylate), starting block $\left(\mathrm{M}_{\mathrm{n}}=15000, \mathrm{PDI}=1.11\right.$, $0.5 \mathrm{~g}, 0.033 \mathrm{mmol})$ was then redissloved in styrene $(1.5 \mathrm{~g}, 14.4 \mathrm{mmol})$, and the mixture was heated at $125^{\circ} \mathrm{C}$ for $8 \mathrm{~h}$. The solidified reaction mixture was dissolved in dichloromethane and precipitated into methanol. The polymer was collected by filtration and dried under high vacuum for $24 \mathrm{~h}$ to give the desired diblock copolymer as a white solid (1.41g, 61\%), $\mathrm{M}_{\mathrm{n}}, 55000 ; \mathrm{PDI}, 1.16$. 


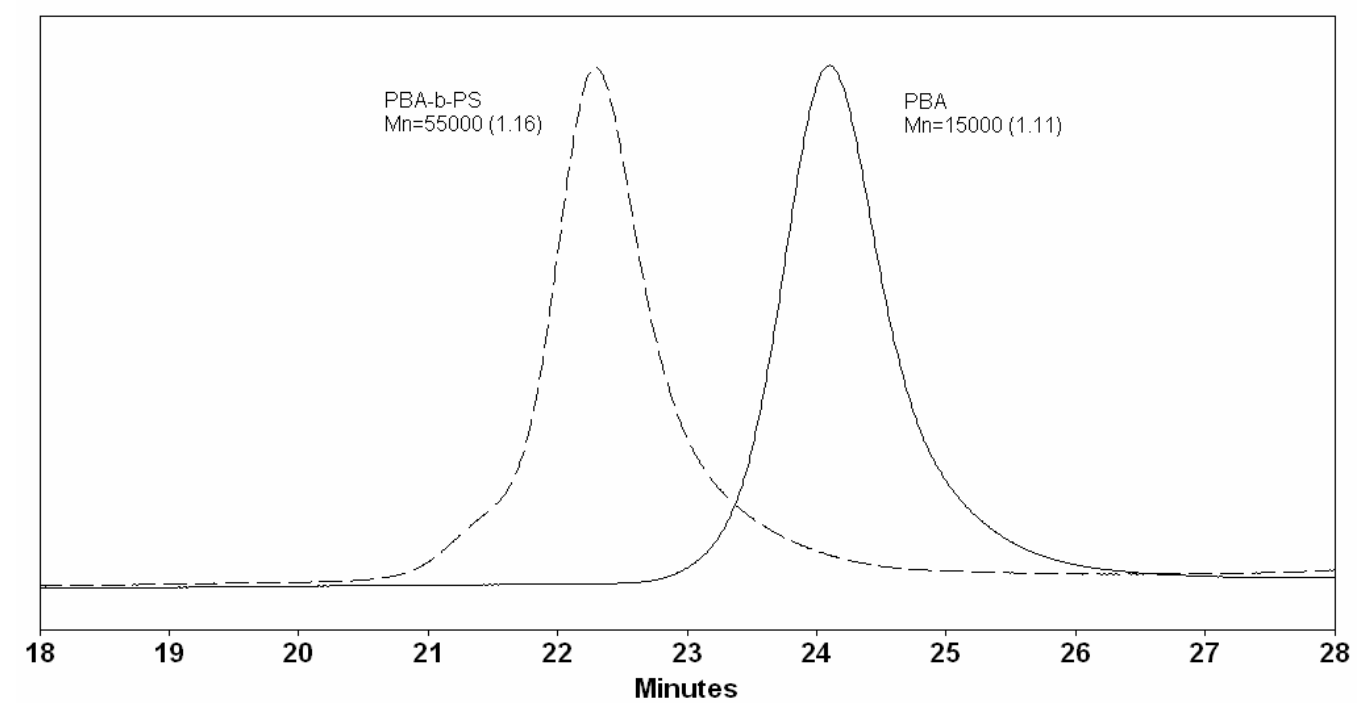

Figure S3. GPC traces for the starting poly(n-butyl acrylate) made by NMP in the presence of alumina (left), and the poly(n-butyl acrylate)-b-polystyrene obtained after chain extension with styrene.

Kinetics study of RAFT polymerization of MA in the presence and absence of acidic alumina. In a $\mathrm{N}_{2}$-filled dry box, a round bottom flask equipped with a magnetic stir bar was charged with MA (2.0 g, $23.3 \mathrm{mmol})$, benzyl 1pyrrocarbodithioate $(0.068 \mathrm{~g}, 0.29 \mathrm{mmol})$, AIBN $(9.5 \mathrm{mg}, 0.058 \mathrm{mmol})$, internal standard tetrachloroethane (TCE, $0.5 \mathrm{~g})$, acidic alumina (0.237 g, 1:10 to monomer) and chlorobenzene $(15 \mathrm{ml})$. The flask was then placed in an oil bath at $60^{\circ} \mathrm{C}$. Samples were taken at specific time intervals using a syringe and analyzed by GC. The conversion of MA was calculated from the integration of MA peak with respect to TCE peak. The molecular weight was measured by GPC. 